\title{
Etnoconhecimento de pequenos agricultores tradicionais sobre plantas medicinais no tratamento de dores provocadas pelo trabalho
}

\author{
Simone Cardoso Ribeiro ${ }^{a}$, Nyrreyne Dias Pereira de Melo ${ }^{b}$, Arthur Bezerra Barros ${ }^{c}$ \\ ${ }^{a}$ Departamento de Geociências, Universidade Regional do Cariri - URCA, Crato, CE, Brasil. \\ bDepartamento de Tecnologia da Informação, Universidade Regional do Cariri - URCA, Crato, CE, Brasil. \\ 'Instituto Juazeiro de Educação Superior, Juazeiro do Norte, CE, Brasil.
}

\begin{abstract}
Resumo: Objetivo: O objetivo desta pesquisa foi verificar o conhecimento etnobotânico dos agricultores da região Cariri do Estado do Ceará, Brasil, no tratamento das dores na coluna e nos músculos provocadas pelo trabalho, considerando-se a cultura e a biodiversidade. Método: Os dados etnobotânicos foram obtidos por meio de entrevistas semiestruturadas, técnica de lista livre e bola de neve, sendo analisados pelos métodos do Discurso do Sujeito Coletivo e do Valor de Uso da Espécie. Resultados: Foram encontradas 18 espécies, sendo que o Barbatimão (Stryphnodendron rotundifolium Mart) e a Sucupira (Bowdichia virgilioides Kunth) foram as espécies mais citadas, apresentando valor de uso de 0,5 e 0,6 , respectivamente. Constatou-se vasta riqueza de informações correlacionas à cultura das comunidades tradicionais estudadas. Conclusão: Conclui-se que compreender as atividades desenvolvidas na agricultura permite a fisioterapia e a terapia ocupacional trabalharem a promoção da saúde dos agricultores, melhorando assim a sua qualidade de vida.
\end{abstract}

Palavras-chave: Medicina Tradicional, Cultura, Interdisciplinaridade.

\section{Traditional knowledge of small farmers on medicinal plants used for occupational pain treatment}

\begin{abstract}
Objective: The research aimed to evaluate the ethnobotanical knowledge of farmers from Cariri, Ceara, Brazil, in the treatment of occupational back and muscles pain, considering the local culture and biodiversity. Method: The ethnobotanical data were obtained through semi-structured interviews, free list technic and snowball, and analyzed by Collective Subject Discourse and species use value methods. Results: We found 18 species; Barbatimão (Stryphnodendron rotundifolium Mart) and Sucupira (Bowdichia virgilioides Kunth) were the most cited species with use-value of 0.5 and 0.6 , respectively. We found a vast wealth of information related to culture of traditional communities studied. Conclusion: Comprehension about the activities developed in agriculture allows occupational therapy to intervene and work to promote the health of farmers thereby improving their quality of life.
\end{abstract}

Keywords: Medicine, Traditional, Culture, Interdisciplinarity.

Autor para correspondência: Nyrreyne Dias Pereira de Melo, Universidade Regional do Cariri, Rua Coronel Antônio Luiz, 1161, CEP 63100-000, Crato, CE, Brasil, e-mail nyrreyne@gmail.com

Recebido em Abr. 14, 2015; $1^{\text {a }}$ Revisão em Out. 26, 2015; 2 ${ }^{a}$ Revisão em Dez. 11, 2015; 3ª Revisão em Fev. 18, 2016 ; Aceito em Abr. 6, 2016. 


\section{Introdução}

A região do Cariri dispóe de rica biodiversidade em espécies, o que torna o local atrativo para pesquisas nos mais diversos âmbitos. É possível encontrar comunidades tradicionais que utilizam suas próprias técnicas, adquiridas através da experiência e dos ensinamentos repassados conforme a tradição oral.

O uso de plantas medicinais por comunidades rurais pode ser observado no tratamento de doenças com o objetivo de melhorar a qualidade de vida do ser humano, sendo ainda parte integrante da cultura nordestina (ALVES; NASCIMENTO, 2010). Segundo Giraldi e Hanazaki (2010, p. 395), “[...] a percepção sobre o poder curativo de algumas plantas é uma das formas de relação entre populações humanas e plantas". Esta prática constitui a alternativa que estas comunidades tradicionais possuem na manutenção da saúde.

A associação do conhecimento tradicional ao cientificismo recebe o nome de Etnociência, a qual aborda o saber das populaçôes tradicionais sobre os processos naturais, tentando descobrir a lógica subjacente ao conhecimento humano do mundo natural, as taxonomias e classificaçóes totais (DIEGUES, 1996). O conhecimento tradicional tem sido imprescindível para analisar os paradigmas dos modelos coloniais e agrícolas de desenvolvimento e servir de base ao desenho de novos modelos alternativos (RIBEIRO, 2012).

O etnoconhecimento advindo da experiência associada ao manejo da terra possui informaçóes que transcendem as mais diversas técnicas utilizadas no plantio; esta riqueza cultural adquirida com o transpor das geraçôes encontra, na subsistência, um dos fatores determinantes para escolha deste meio de vida. Os modelos de cultura e conhecimento baseiam-se em processos históricos, linguísticos e culturais, e apesar de não se isolarem das histórias mais amplas, retêm certa especificidade de lugar (ESCOBAR, 2005).

Relacionado às Disfunçôes Osteomusculares Relacionadas ao Trabalho - DORTs, Santos e Lima Neto (2014), em sua pesquisa sobre prevalência de DORT em trabalhadores, relataram que as LERs representam a principal causa de adoecimento devido ao trabalho interferindo na capacidade para o trabalho, comprometendo ainda a qualidade de vida do trabalhador rural ou urbano. Essas alteraçôes promovem a diminuição do bem-estar físico e mental, e a redução da motivação para o trabalho e da satisfaçáo pessoal, demonstrando assim a importância deste trabalho de pesquisa de plantas medicinais que podem ser utilizadas no tratamento de DORT.

Para Gemma, Tereso e Abrahão (2010), pessoas que trabalham na agricultura desempenham diversas tarefas relacionadas aos sistemas de trabalho em posturas físicas desconfortáveis, que requerem grandes esforços, em especial o plantio, os tratos culturais e a colheita, por serem exercidos de forma manual.

Uma vez que o Terapeuta Ocupacional trabalha com o ser humano de forma holística, fornecendo assistência na promoção e prevenção de agravos, considerando ainda o contexto histórico ocupacional das comunidades, este estudo objetivou identificar o conhecimento popular, conforme a cultura de pequenos agricultores cearenses, acerca do uso de plantas medicinais no tratamento de dores osteomusculares provocadas pelo exercício na agricultura.

\subsection{Conhecimento popular no uso de plantas medicinais}

Cada local possui um conjunto de rituais específicos e manejo na utilizaçáo de plantas medicinais. O termo População Tradicional transcende as perspectivas, envolvendo teorização, e engloba políticas ambientais, territoriais e tecnológicas. Apresenta dificuldades, quanto à definição, por envolver diversos organismos multilaterais difundidos pela tradição oral destas populaçôes (PEREIRA; DIEGUES, 2010).

Segundo Costa (2012), a Terapia Ocupacional no contexto social, uma vez que participa da discussão sobre os Povos e Comunidades Tradicionais - PCT, confere atuação direta na garantia dos direitos humanos. A representaçáo destas comunidades em pesquisas etnobotânicas exprime parte da riqueza em informaçóes transmitidas no decorrer das gerações.

Para Maciel et al. (2002, p. 429),

[...] o conhecimento sobre plantas medicinais simboliza muitas vezes o único recurso terapêutico de muitas comunidades e grupos étnicos. O uso de plantas no tratamento e na cura de enfermidades é tão antigo quanto a espécie humana.

A união entre a Ecologia Humana e a Antropologia Cognitiva resulta na Etnobiologia, que busca entender como o mundo é percebido, conhecido e classificado pelas diferentes culturas humanas (BEGOSSI, 1993).

No final do século XIX, a Etnobiologia já era citada com uma nomenclatura diferente. Inicialmente, o conhecimento cultural era visto de modo simples e utilitarista. Por volta da década de 1960, foi influenciado pela Antropologia e, decorrente deste processo, 
tornou-se uma fonte teórica para a experimentação de um tipo de integração de conhecimentos e práticas que enfatizavam discussóes, as quais interfaciavam as consequências ambientais e o desenvolvimento do conhecimento humano para manter a sobrevivência dos grupos humanos em suas bases territoriais ecossistêmicas (SANTOS; SENA, 2010).

Posey (1987) define Etnobiologia como estudo do saber e conceituaçóes acerca da biologia; através da ecologia humana, enfatiza categorias e conceitos cognitivos em um determinado grupo de estudo. Existe a necessidade de uma visão interdisciplinar que relacione os mundos natural, simbólico e social estabelecidos por diferentes culturas. O termo foi descrito no século XIX nos Estados Unidos da América - EUA, decorrente do contraste entre o saber tradicional dos índios e o conhecimento científico proveniente dos europeus. A partir da Conferência do Rio sobre Meio Ambiente (1992), o termo etnobiodiversidade é enfatizado, tendo por base os estudos etnobotânicos (SZABÓ, 1998).

Segundo Eloy (2014, p. 190):

A expressão "conhecimento tradicional" está impregnada de sentidos e, por se tratar de termo ainda recente na literatura, apresenta várias denominaçóes, embora a maioria se mostre imprecisa, náo havendo, portanto, um consenso entre os teóricos da área sobre seu real significado. Além de possuir múltiplos conceitos, o conhecimento tradicional também é designado por vários termos, que se associam em geral ao tipo de comunidade detentora, tais como: "Conhecimento Local" (LK, Local Knowledge), "Conhecimento Ecológico Tradicional" (TEK, Traditional Ecological Knowledge), "Conhecimento Indígena" (LK, Indigenous Knowledge), "Conhecimento Ecológico e Sistemas de Manejo Tradicionais" (TEKMS, Traditional Ecological Knowledge and Management Systems), "Conhecimento dos Habitantes Rurais" (Rural Peoples Knowledge), "Conhecimento dos Produtores" (FK, Farmers Knowledge) e "Conhecimento Comunitário” (Community Knowledge). Entretanto, tais termos apesar de serem distintos abordam o mesmo significado.

A Resolução n. ${ }^{\circ} 406$ de 07 de novembro de 2011 para o exercício da especialidade profissional em Terapia Ocupacional nos contextos sociais ressalta que é necessário o domínio das grandes áreas de competência, entre as quais:

[...] realizar histórias ocupacionais e condição de participação na comunidade em que habitam a fim de desenvolver estratégias de adaptaçóes ambientais e urbanísticas, mobilidade, acessibilidade, pertencimento sociocultural e econômico e outras tecnologias de suporte para inclusão sociocomunitária para o acompanhamento de pessoas, grupos e famílias e comunidades urbanas, rurais e tradicionais (BRASIL, 2011).

Desta forma, é imprescindível insistir no fato de que a Terapia Ocupacional, ao trabalhar com a sociedade e a cultura, exprime a valorizaçáo das formas socioculturais de expressão, a qual se reflete na tradição oral das comunidades tradicionais.

A relação do homem com a natureza é imprescindível e a cultura popular recebe atenção diferenciada, em que a utilização de plantas e animais para tratamentos de doenças não é algo novo, transcende os valores econômicos e, com o auxílio dos diversos profissionais relacionados à biodiversidade, há uma ampliação do conhecimento e das técnicas preservativas no meio em que o homem está incluso e que, por vezes, ele é responsável pela modificação do ambiente.

\subsection{A Terapia Ocupacional frente à cultura das comunidades tradicionais}

O Terapeuta Ocupacional, dentro do contexto social, deve trabalhar vinculado a comunidades tradicionais, considerando os princípios éticos e a diversidade apresentada por estas, e deve ainda atuar de forma multidisciplinar e dinâmica, respeitando o processo histórico vivenciado pelos povos (BRASIL, 2011).

Geertz (1978, p. 14) afirma que:

O conceito de cultura que eu defendo [...] é essencialmente semiótico. Acreditando, como Max Weber, que o homem é um animal amarrado a teias de significados que ele mesmo teceu, assumo a cultura como sendo essas teias e a sua análise; portanto, não como uma ciência experimental em busca de leis, mas como uma ciência interpretativa, à procura do significado. É justamente uma explicação que eu procuro, ao construir expressões sociais enigmáticas na sua superfície.

De acordo com Costa (2012), o trabalho da Terapia Ocupacional com a sociedade envolve a participação em projetos que ampliem o vínculo entre as relaçôes sociais e ambientais, e os contextos sócio-históricos.

O conhecimento da população tradicional é essencial para o desenvolvimento de pesquisas, 
uma vez que este resulta da interaçáo direta entre o ser humano e o meio ambiente. A utilização de plantas medicinais é uma das mais antigas práticas empregadas para tratamento de enfermidades humanas. De acordo com Amoroso e Gely (1988), são espécies vegetais utilizadas para fins específicos, empregadas na prevenção, no tratamento e na cura de distúrbios, disfunçôes ou doenças do ser humano e dos animais.

A Política Nacional para o Desenvolvimento Sustentável de Povos e Comunidades Tradicionais - PNPCT instituída em 2007, através do Decreto 6.040 do Governo Federal, objetiva a promoção do desenvolvimento sustentável dos Povos e Comunidades Tradicionais, enfatizando:

[...] o reconhecimento, fortalecimento e garantia dos seus direitos territoriais, sociais, ambientais, econômicos e culturais, com respeito e valorizaçáo à sua identidade, suas formas de organização e suas instituiçôes [...] (BRASIL, 2007).

Encontra-se entre os princípios da PNPCT:

O reconhecimento, a valorizaçáo e o respeito à diversidade socioambiental e cultural dos povos e comunidades tradicionais, levando-se em conta, dentre outros aspectos, os recortes etnia, raça, gênero, idade, religiosidade, ancestralidade, orientação sexual e atividades laborais, entre outros, bem como a relação desses em cada comunidade ou povo, de modo a não desrespeitar, subsumir ou negligenciar as diferenças dos mesmos grupos, comunidades ou povos ou, ainda, instaurar ou reforçar qualquer relação de desigualdade;(...)a preservação dos direitos culturais, o exercício de práticas comunitárias, a memória cultural e a identidade racial e étnica (BRASIL, 2007).

Para Casagrande, Mariotti e Cardoso (2015), a Terapia Ocupacional, no exercício da profissão, reúne conhecimentos de diversas disciplinas da saúde, da educação social e da cultura. O Terapeuta Ocupacional, segundo as funçôes estabelecidas pelo Código de Ética e Deontologia, atende o ser humano de forma individual e coletiva, atuando nos três níveis de atenção à saúde, respeita os aspectos socioculturais sem discriminação, conforme o sistema de saúde, de assistências social, educacional e cultural brasileiro.

\section{Método}

\subsection{Localização e caracterização da área de estudo}

O estudo foi realizado no Sítio Santo Antônio, que se localiza em Arajara, distrito de Barbalha-CE (Figura 1); é uma área rural, encosta norte da Chapada

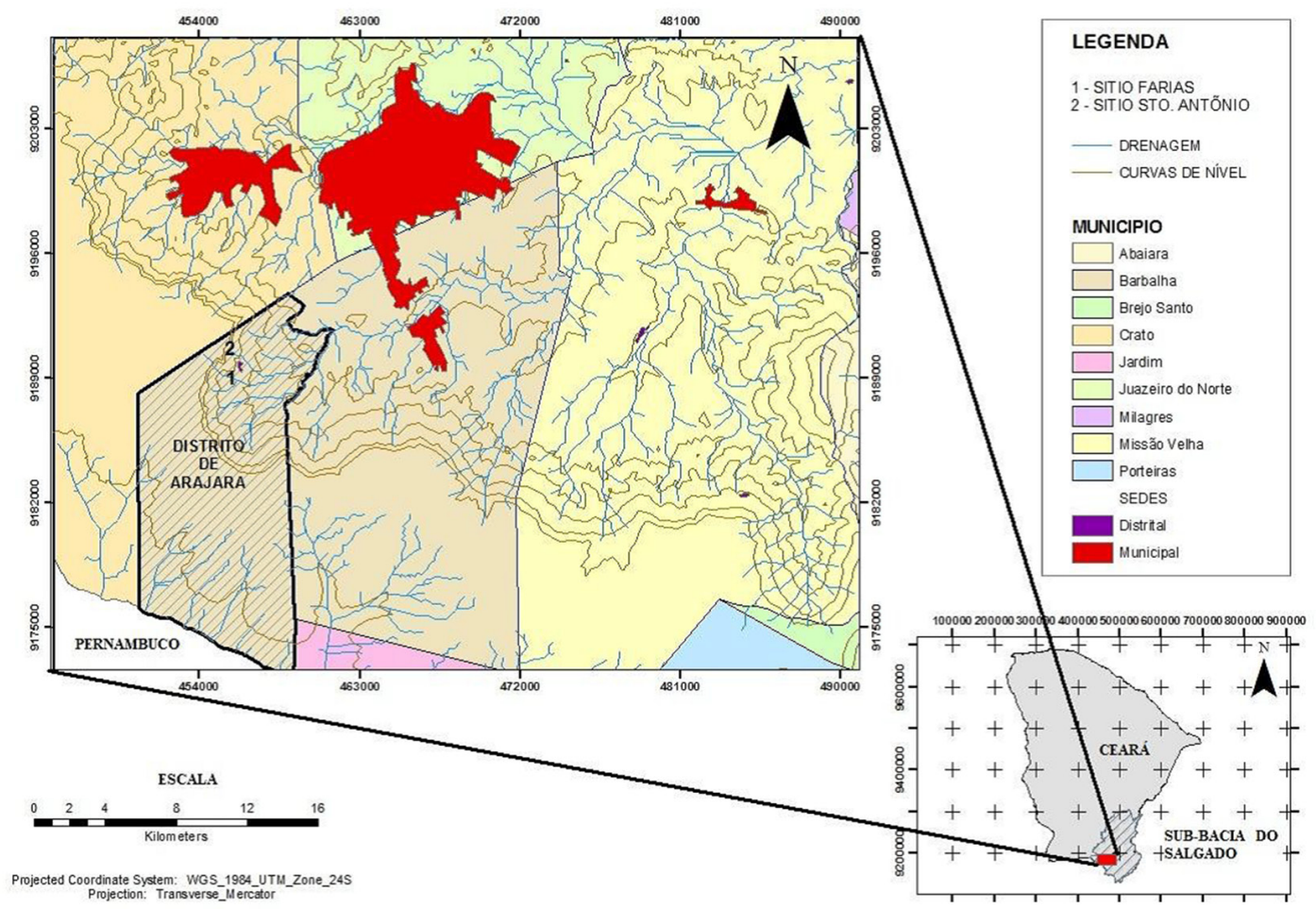

Figura 1. Localização da área estudada. Fonte: Dados adaptados de Ribeiro (2012). 
do Araripe, localizada no Cariri Cearense, caracterizada pela vida agrícola e pela alta diversidade de plantas medicinais e espécies.

Conforme dados do Instituto Brasileiro de Geografia e Estatística - IBGE (INSTITUTO..., 2015), a população residente em Barbalha compreende 58.347 habitantes, com área de 569, $508 \mathrm{~km}^{2}$, sendo a densidade demográfica de $97,14 \mathrm{hab} / \mathrm{km}^{2}$. Encontra-se a $553 \mathrm{~km}$ de Fortaleza, capital do Ceará, possuindo latitude de $7^{\circ} 18^{\prime} 18^{\prime \prime} \mathrm{S}$ e longitude de $39^{\circ} 18^{\prime} 7^{\prime \prime} \mathrm{W}$, localizada na Mesorregião do Sul Cearense, ao lado da Chapada do Araripe. A comunidade Santo Antônio ocupa, de forma permanente ou temporária, territórios tradicionais; faz uso de recursos naturais, condicionando-o como uma ferramenta para a reprodução cultural, social, religiosa, ancestral e econômica da comunidade, e vale-se principalmente de conhecimentos e de práticas oriundas pela tradição oral (HAVERROTH, 2013).

\subsection{Coleta de dados}

Foi traçado um método baseado na pesquisa Etnoecológica, caracterizado como um estudo de caso de natureza quantiqualitativa: quantitativa, na perspectiva de obter uma amostragem probabilística do total de sujeitos entrevistados, e qualitativa, na forma como os dados foram obtidos e analisados. Foram realizadas as seguintes etapas: levantamento bibliográfico; pesquisa de campo, que incluiu visitas prévias no intuito de gerar um vínculo inicial com as comunidades tradicionais, consideradas assim em decorrência do período de permanência no território que habitavam - havia mais de 20 anos, segundo entrevistados; entrevista com os sujeitos de pesquisa sobre plantas medicinais usadas no tratamento de DORT, e análise de dados.

Foram realizadas visitas informais na comunidade do sítio Santo Antônio em Arajara-CE e, no segundo momento, os participantes foram entrevistados e selecionados segundo o método "bola de neve"; neste método, eles indicavam outros trabalhadores rurais considerados especialistas quanto ao entendimento sobre plantas medicinais. Para coleta de dados, foram utilizados: a listagem livre e o Discurso do Sujeito Coletivo - DSC.

As espécies coletadas foram: Chenopodium ambrosioides; Magnoliophyta; Ditassa; Copaifera spp.; Bowdichia virgilioides; Ocimum gratissimum; Myracrodruon urundeuva; Persea americana; Plectranthus amboinicus; Caesalpinia férrea e Stryphnodendron rotundifolium. Já o DSC reuniu o conjunto de respostas sobre o uso destes recursos em uma só fala, o qual representou o todo. O Discurso do
Sujeito Coletivo (DSC) é uma técnica de tabulação e organização de dados qualitativos, o qual se baseia na autoexpressão do pensamento ou opinião coletiva, permitindo análise qualitativa e quantitativa destes (FIGUEIREDO; CHIARI; GOULAR, 2013).

Durante os contatos realizados, seja em visitas às casas, seja acompanhando as atividades cotidianas, as informaçôes ou os dados obtidos foram anotados imediatamente em um "caderno de dados". Para cada espécie, foi calculado o Valor de Uso (UV), conforme metodologia empregada por Phillips e Gentry (1993). Para calcular o Valor de Uso de cada espécie (UV), utiliza-se a seguinte fórmula:

$$
U V_{s}=S U V_{i s} / n
$$

Em que:

$\mathrm{UV}_{\mathrm{is}}=$ valor de uso de uma espécie para um participante;

$\mathrm{n}=$ número total de informantes entrevistados.

Quanto mais próximo de um (1), maior o valor de uso da espécie. SUV é o somatório do número de vezes que a espécie é citada.

\section{Resultados e Discussão}

A amostra foi constituída por dez pessoas, sendo oito do sexo feminino; a faixa etária foi de 39 a 86 anos; de acordo com o estado civil, seis eram casados, três solteiros e um viúvo. O nível de escolaridade expressou que um (10\%) é analfabeto, quatro (40\%) possuem Ensino Fundamental e cinco (50\%) Ensino Médio. Dos entrevistados, alguns, além de exercerem um trabalho na agricultura, desenvolviam ainda trabalhos domésticos na própria residência. Houve prevalência de mulheres na participaçáo da pesquisa, o que pode ainda ser explicado pelo número pequeno de entrevistados.

Um estudo etnobotânico realizado por Bandeira, Silva e Brito (2015), na comunidade Lagoa do Porão, Jatobá do Piauí, com um grupo amostral igual de agricultores, evidenciou que $80 \%$ eram do sexo feminino, o que se justifica pela própria população brasileira ter em sua composição mais mulheres do que homens. Além disso, o trabalho com espécies geralmente é realizada por mulheres, apresentando ainda trabalho com espécies medicinais.

Em relação ao nível de escolaridade, conforme indicado - 1 (10\%) é analfabeto, 4 (40\%) possuem Ensino Fundamental e 5 (50\%), Ensino Médio - os dados deste trabalho diferem do estudo de Bandeira, Silva e Brito (2015), no qual 70\% não possuíam o Ensino Fundamental completo, 20\% nunca 
frequentaram a escola e apenas $10 \%$ possuíam o Ensino Fundamental completo. A escolaridade interfere no uso das plantas medicinais à medida que os que possuem estudo podem ofertar mais aparato no manejo ao solo.

No estudo, foi evidenciado que não apenas os idosos como também os mais jovens dispóem de um saber acerca das plantas medicinais; portanto, percebe-se que a tradição permanece, pois apesar dos recursos farmacológicos disponíveis, ainda são utilizadas as plantas como recurso terapêutico. Poder-se-ia achar alguma referência que fale sobre isto também.

Das plantas indicadas no estudo, foram encontradas 18 espécies, sendo que as mais citadas foram a Sucupira (Bowdichia virgilioides Kunth) e Barbatimão (Stryphnodendron rotundifolium Mart), com valores de uso de 0,6 e 0,5, respectivamente. As partes utilizadas foram: raiz, folha, casca, semente e, fruto, sendo que alguns extraíram o leite da planta. Quanto à via de administração, 100\% utilizaram a via oral; quanto à forma de preparo, foram utilizados: infusão ${ }^{1}$, decocção ${ }^{2}$, de molho $^{3}$ e lambedor ${ }^{4}$ (Tabela 1). Durante as entrevistas com os sujeitos de pesquisa, os nomes das plantas e animais foram registrados conforme pronunciados pelos informantes.

Estas indicaçóes vão ao encontro dos achados no DSC, que sugere o uso da planta para dores osteomusculares e da coluna, em sua totalidade.

Segundo o modelo de Lefevre e Lefevre (2015), o Discurso do Sujeito Coletivo - DSC permitiu aplicar uma análise de dados enfatizando a subjetividade na resposta das comunidades tradicionais como uma única voz. Conforme a pesquisa, quando questionados sobre a atividade que exerciam, se requeria utilização de força e trabalho repetitivo, esta respondeu que

o trabalho exige força, pego muito peso, trabalho é repetitivo, levanto, sento, me abaixo muito sempre o mesmo movimento, na enxada o braço dói, trabalho na roça e em casa, é repetitivo até pra varrer o terreiro, não tem tempo pra descansar direito tudo é pesado, também repetitivo.

A Tabela 2 expressa a divisão relativa às categorias de DORTs que poderiam ser mencionadas segundo a prevalência descrita na literatura; porém, não houve citação dos entrevistados específica para apenas uma indicação, pois cada participante citou mais de uma DORT, ou seja, relacionando Bursite com dores musculares, e náo apenas dores musculares ou bursite como citação única, o que engradou mais de uma das respostas enquadradas na categoria E, em outras DORTs.

Os resultados quantitativos, segundo a Ideia Central, apontaram prevalência de dores na coluna, com $53,57 \%$ das indicaçóes.

Não houve citação nas categorias B, C e D de forma isolada. Os entrevistados indicaram mais de uma doença se enquadrando na categoria $\mathrm{E}$, porque cada participante indicou mais de uma regiáo com dor no seu discurso, o que as enquadrou na categoria $\mathrm{E}$.

A Tabela 3 traz o DSC conforme indicaçôes dos recursos naturais para todas as espécies medicinais utilizadas para tratamento de DORTs, de acordo com a enfermidade. No estudo de Macedo e Ferreira (2005), relatou-se que as espécies mais frequentes encontradas na literatura, no tratamento de hipoglicemiantes, são $M$. charantia, A. humile, $H$. speciosa, B. rufa, $B$. virgilioides, $H$. aphrodisiaca e $S$. paniculatum. Franco e Barros (2006), em seu estudo, afirmam que a Sucupira é utilizada no tratamento não só da coluna como também de gripe, dor de cabeça e inflamação. Já Macedo (2013) evidenciou que não só a Sucupira como também Barbatimão têm as seguintes indicaçôes para tratamento: úlcera, gastrite, dor no estômago, queimação, azia, dor de barriga, indigestão, gastura, nascimento de dente, dor de dente, hérnia, reumatismo e dores na coluna.

Resultados semelhantes foram encontrados na pesquisa de Negri et al. (2014), que evidenciaram que, apesar de a amostra total em seu estudo referir dor em decorrência do trabalho, o membro superior associado a dores na coluna foi a queixa principal de 55,5\% da população, verificada em 1.007 prontuários com diagnóstico de DORTs. Isto constata que as principais DORTs identificadas nesta pesquisa são, de fato, as mais comuns dentre os trabalhadores.

De acordo com Brito et al. (2015), a lombalgia é uma das maiores causas de incapacidade funcional de longa e curta duração entre os trabalhadores, o que envolve, assim, os agricultores em decorrência das más posturas e longas jornadas de trabalho com poucos intervalos de descanso, e ainda da presença de atividades repetitivas. Este fator, associado à maior parte das indicaçóes de plantas medicinais usadas no tratamento de dor na coluna, pode ser justificado pelo fato de esta ser a dor mais recorrente no meio rural.

De acordo com Walcker e Romão (2010), no estudo com agricultores, observou-se que $53,4 \%$ destes apresentaram dores e a coluna vertebral foi a mais acometida, com $56,4 \%$ das queixas, sendo que $30,1 \%$ correlacionaram essa dor ao trabalho exercido no manejo da terra. Dados semelhantes 


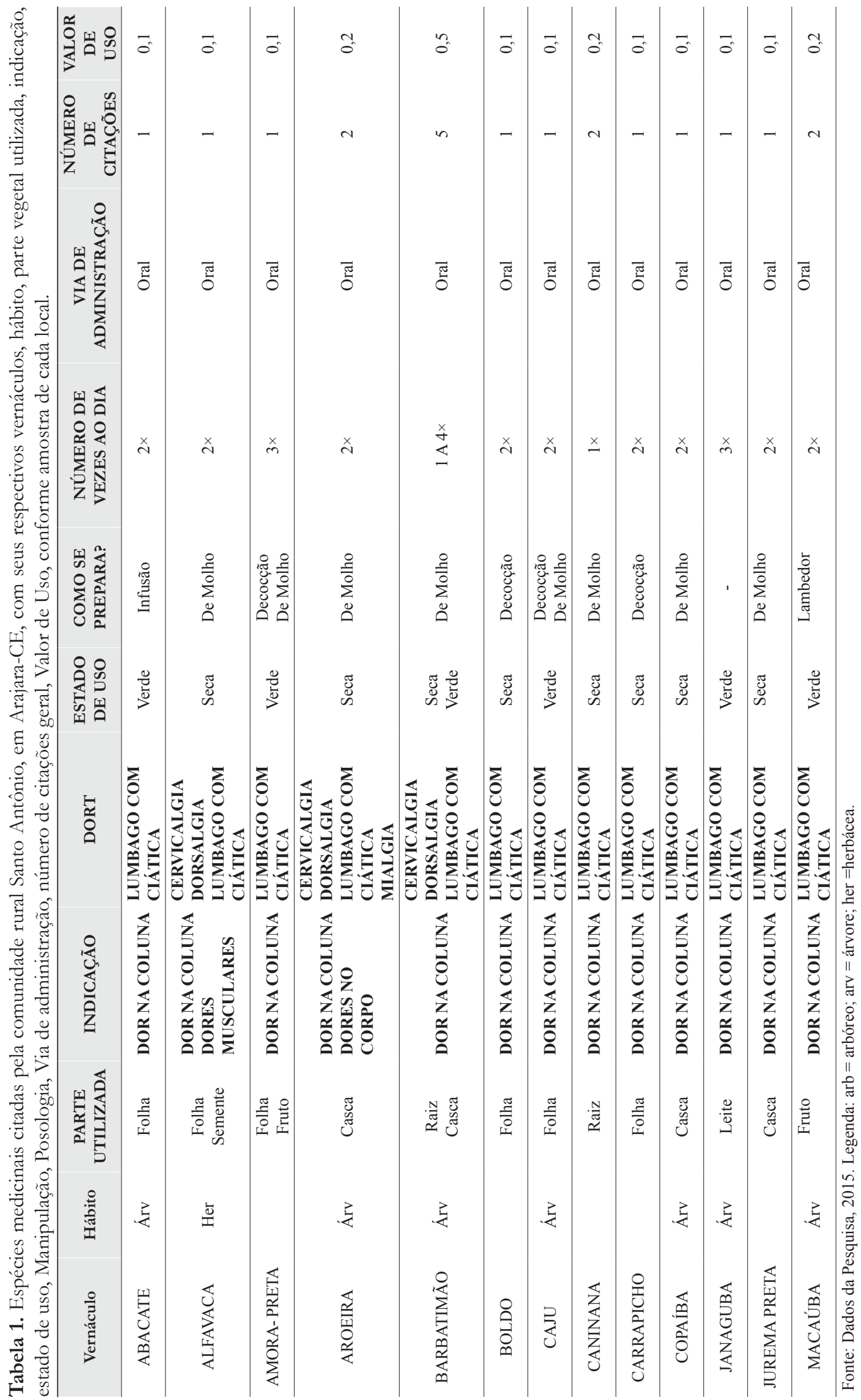




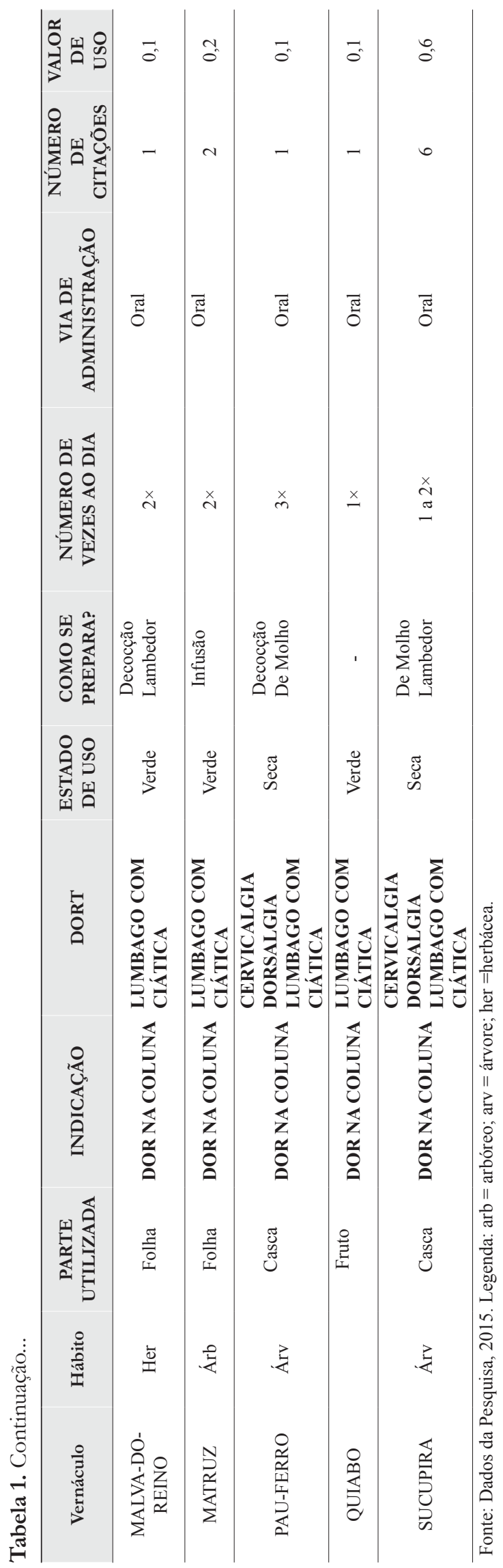


Tabela 2. Categorias de DORTs utilizadas para o Discurso do Sujeito Coletivo - DSC.

\begin{tabular}{cc}
\hline A & Dor na coluna \\
B & Dores musculares \\
C & Bursite \\
D & Tendinite \\
E & Outras DORTs \\
F & Dores musculares e na coluna \\
\hline
\end{tabular}

Tabela 3. DSC conforme indicações dos recursos naturais para todas as espécies medicinais utilizadas para tratamento de DORTs, de acordo com a enfermidade.

UTILIZA PLANTAS OU ANIMAIS MEDICINAIS NO TRATAMENTO DE DOENÇAS RELACIONADAS AO SEU TRABALHO? QUAIS SÃO AS INDICAÇÕES?

DSC A: As plantas são usadas para dores na coluna

DSC GERAL

Qualquer dor ou problema na coluna pode ser usado, nos quartos ou bacia, e na coluna toda.

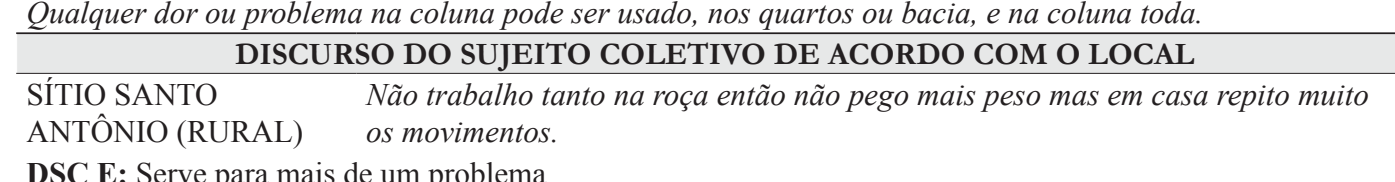

DSC E: Serve para mais de um problema

\section{DSC GERAL}

Serve pra tudo, dor nas costas perto da pá, dor no mucumcubuco, nas carnes, bacia nas pernas também, dor na coluna e no ombro aquela do nome bem conhecido; coluna na altura das cadeiras, nos músculos, nas costas, bursite na coluna toda até pra os ossos serve.

foram encontrados nesta pesquisa, uma vez que $70 \%$ das indicaçóes, na zona rural, foram a coluna, com ênfase na regiăo lombar, sendo este um dos fatores que predispóem ao aparecimento das DORTs.

Para Oliveira et al. (2012), as comunidades tradicionais vivem com grande diversidade de espécies vegetais, desenvolvendo maneiras particulares de explorá-las para distintas finalidades, usando-as para própria subsistência. Diante do repertório cultural, as plantas para fins terapêuticos são uns dos métodos utilizados diante do saber empírico. Já Haverroth (1997) ressalta que este saber dentro da Etnobiologia vai além de uma visão compartimentada, pois engloba as áreas de etnozoologia, etnoecologia, etnoentomologia, etnofarmacologia e etnomedicina. Albuquerque (1997) afirma ainda que as investigaçóes etnobotânicas ofertam aporte para programas em que se enfatiza o conhecimento tradicional dos complexos sistemas de manejo e conservaçáo dos recursos naturais dos povos tradicionais, promovendo o reconhecimento e a preservaçáo de plantas em seu habitat. O conjunto de saberes tradicionais fornece um arsenal de recursos medicinais alternativos que podem ser utilizados pela Terapia Ocupacional.

Freitas e Garcia (2012, p. 13) afirmam que

[...] ainda há muito por fazer para conhecer melhor e prevenir as doenças e os acidentes relacionados ao trabalho na agropecuária e promover a saúde da populaçáo direta e indiretamente envolvida.

Os autores ressaltam que o conjunto de relaçôes de trabalho que ocorrem na agricultura vinculada à precariedade e à intensificação do trabalho afeta a saúde dos que trabalham no campo e o recurso alternativo das plantas medicinais pode contribuir para minimizar os problemas decorrentes do trabalho agrícola.

Para Casagrande, Mariotti e Cardoso (2015, p. 432),

[...] a terapia ocupacional pode ser um elemento importante na construçáo de novos caminhos para a atenção à saúde, integral, globalizante e na perspectiva da totalidade, subjetividade e singularidade dos indivíduos.

Atender o ser humano de forma global possibilita a profissão compreender o indivíduo dentro das relaçôes estabelecidas interpessoais e com o próprio ambiente no qual está inserido, e justifica ainda o interesse por recursos medicinais alternativos dispostos neste estudo.

De acordo com Vaz (2015), a atuação da Terapia Ocupacional na Saúde do Trabalhador ainda está na fase inicial e é imprescindível que novas estratégias sejam inclusas para melhor atender as expectativas e 
necessidades dos trabalhadores das mais diversas áreas. O processo cultural está diretamente relacionado ao manejo da terra e o uso dos recursos naturais, a compreensão deste processo de aprendizado adquirido com a transição das gerações torna o profissional da saúde ativo na saúde dos agricultores inseridos nas comunidades tradicionais, observadas no presente artigo.

Uma vez que a Terapia Ocupacional é a ciência que estuda a atividade humana buscando prevenir e tratar as dificuldades físicas ou psicossociais, engaja-se diretamente no processo de busca de recursos paliativos, tal como nesta pesquisa, na promoção da saúde dos trabalhadores rurais. Este artigo fornece base para novas pesquisas valorizando o saber tradicional e popular, que demonstrou ser de importante representação na vida dos trabalhadores rurais. Observe-se que, para esses trabalhadores, medicamentos sintéticos são de difícil acesso, o que justifica ainda o uso destes recursos naturais. O fato de algumas plantas terem sido mais citadas que outras foi decorrente do uso constante e do acesso à planta.

\section{Conclusão}

A região do Cariri possui não só uma alta diversidade de espécies medicinais como também uma vasta riqueza no contexto cultural, expressa na sabedoria popular adquirida de geração em geração. A cultura popular das comunidades agrárias é fundamental nos estudos etnobotânicos e as repercussôes socioambientais e de saúde decorrentes das mudanças nos processos produtivos e das transformaçóes do mundo do trabalho afetam a qualidade de vida do trabalhador.

O Terapeuta Ocupacional é um profissional da saúde que atua em todos os níveis de atenção à saúde e, com sua formação generalista, trabalha de forma direta nas políticas sociais. Uma vez que garante a integralidade da assistência em todos os níveis de complexidade, o Terapeuta Ocupacional dispóe de instrumentos para fortalecimento dos saberes tradicionais.

Conforme Vaz (2015, p. 34), as atuações terapêuticas ocupacionais mais frequentes são:

[...] atuação multidisciplinar, reabilitação profissional, vigilância em saúde do trabalhador, ergonomia e os processos de atuação do terapeuta ocupacional que são as avaliaçóes iniciais e finais, e as avaliaçôes ergonômicas nas empresas.

Exprime-se, dessa forma, a vasta participação deste profissional no exercício de suas atribuiçóes.
Este colabora também na discussão e na articulação de propostas voltadas para o desenvolvimento local sustentável ao atender as necessidades dos agricultores, considerando os aspectos socioculturais. Contribui também para a mudança e a melhoria das condições de saúde do indivíduo e do coletivo.

Desse modo, os profissionais de saúde, tal como os Terapeutas Ocupacionais, em uma atuação multidisciplinar, são incentivados, através das comunidades tradicionais e dos recursos presentes em sua cultura, a acrescentar em sua prática assistencial terapêuticas que possibilitem um maior contato e a preservação do saber popular. Mostra-se possível, ainda, a inclusão de novos recursos alternativos no tratamento de doenças e na melhora da qualidade de vida do trabalhador rural.

Este estudo visou a contribuir para pesquisas científicas, valorizando o conhecimento transmitido com o passar das geraçóes e a diversidade de recursos medicinais, que podem ser utilizados para tratamento de dores relacionadas aos trabalhos, uma vez que este estudo é quase inexistente na literatura. A interface Terapia Ocupacional e Saúde do Trabalhador é um campo novo de atuaçáo, na medida em que se instiga a busca por novos estudos, almejando o aperfeiçoamento pelos profissionais e o fortalecimento do conhecimento tradicional.

\section{Referências}

ALBUQUERQUE, U. P. Etnobotânica: uma aproximação teórica e epistemológica. Revista Brasileira de Farmácia, Rio de Janeiro, v. 78, n. 3, p. 60-64, 1997.

ALVES, J. J. A.; NASCIMENTO, S. S. Levantamento fitogeográfico das plantas medicinais nativas do cariri paraibano. Revista Geográfica Acadêmica, Boa Vista, v. 4, n. 2, p. 73-85, 2010.

AMOROSO, M. C. M.; GELY, A. Uso de plantas medicinais por caboclos de Baixo Amazonas. Boletim Museu Paraense Emílio Goeldi, Belém, v. 4, n. 1, p. 47-131, 1988.

BANDEIRA, L. R. G. S.; SILVA, M. D. S.; BRITO, R. C. T. Uso de plantas medicinais cultivadas na comunidade Lagoa do Porão, Jatobá do Piauí. Revista Interdisciplinar, Teresina, v. 8, n. 1, p. 55-61, 2015.

BEGOSSI, A. Ecologia Humana: um enfoque das relaçôes homem-ambiente. Interciência, Campinas, v. 18, n. 1, p. 121-132, 1993.

BRASIL. Decreto no 6.040, de 7 de fevereiro de 2007. Institui a Política Nacional de Desenvolvimento Sustentável dos Povos e Comunidades Tradicionais. Diário Oficial [da] República Federativa do Brasil, Brasília, DF, 8 fev. 2007. 
BRASIL. Resolução n ${ }^{\circ}$ 406, de 07 de novembro de 2011. Disciplina a Especialidade Profissional Terapia Ocupacional nos Contextos Sociais e dá outras providências. Diário Oficial [da] República Federativa do Brasil, Poder Executivo, Brasília, DF, 24 nov. 2011.

BRITO, J. S. et al. Prevalência de lombalgias musculoesqueléticas dependentes em comerciários. Sanare - Revista de Politicas Públicas, Sobral, v. 14, p. 1-1, 2015. Suplemento 1.

CASAGRANDE, R. P.; MARIOTTI, M. C.; CARDOSO, M. M. Contribuiçóes da Terapia Ocupacional no apoio e assistência a familiares de pessoas com transtornos mentais. Cadernos de Terapia Ocupacional da UFSCar, São Carlos, v. 23, n. 2, p. 427-437, 2015.

COSTA, S. L. Terapia Ocupacional Social: dilemas e possibilidades da atuaçáo junto a Povos e Comunidades Tradicionais. Cadernos de Terapia Ocupacional da UFSCar, São Carlos, v. 20, n. 1, p. 43-54, 2012.

DIEGUES, A. C. Repensando e recriando as formas de apropriação comum dos espaçose recursos naturais. In: VIEIRA, P. F.; WEBER, J. (Org.). Gestão de recursos naturais renováveis e desenvolvimento. São Paulo: Cortez Editora, 1996. p. 97-124.

ELOY, C. C. et al. Apropriação e proteção dos conhecimentos tradicionais no Brasil: a conservaçáo da biodiversidade e os direitos das populaçóes tradicionais. Revista Gaia Scientia, João Pessoa, v. 8, n. 1, p. 189-198, 2014.

ESCOBAR, A. O lugar da natureza e a natureza do lugar: globalização ou pós-desenvolvimento? In: LANDER, E. (Org.). A colonialidade do saber: eurocentrismo e ciências sociais. Ciudad Autônoma de Buenos Aires: CLACSO, 2005. p. 133-168.

FIGUEIREDO, M. Z. A.; CHIARI, B. M.; DE GOULART, B. N. G. Discurso del Sujeto Colectivo: una breve introducción a la herramienta de investigación cualitativa y cuantitativa. Distúrb Comun, São Paulo, v. 25, n. 1, p. 129-136, 2013.

FRANCO, E. A. P. A.; BARROS, R. F. M. Uso e diversidade de plantas medicinais no Quilombo Olho D'água dos Pires, Esperantina, Piauí. Revista Brasileira de Plantas Medicinais, Botucatu, v. 8, n. 3, p. 78-88, 2006.

FREITAS, C. M.; GARCIA, E. G. Trabalho, saúde e meio ambiente na agricultura. Revista Brasileira de Saúde Ocupacional, São Paulo, v. 37, n. 125, p. 12-16, 2012. http:// dx.doi.org/10.1590/S0303-76572012000100003.

GEERTZ, C. A. Interpretação das culturas. Rio de Janeiro: Zahar Editores, 1978.

GEMMA, S. F. B.; TERESO, M. J. A.; ABRAHÃO, R. F. Ergonomia e complexidade: o trabalho do gestor na agricultura orgânica na regiáo de Campinas - SP. Ciência Rural, Santa Maria, v. 40, n. 2, p. 318-324, 2010.

GIRALDI, M.; HANAZAKI, E. N. Uso e conhecimento tradicional de plantas medicinais no Sertáo do Ribeirão. Acta Botanica Brasilica, Florianópolis, v. 24, n.
2, p. 395-406, 2010. http://dx.doi.org/10.1590/S010233062010000200010 .

HAVERROTH, M. K. Um Estudo Etnobotânico: o uso e a classificação das plantas na área Indígen a Xapecó (oeste de SC). 1997. 175 f. Dissertação (Mestrado em Antropologia Social) - Universidade Federal de Santa Catarina, Florianópolis, 1997.

INSTITUTO BRASILEIRO DE GEOGRAFIA E ESTATÍSTICA - IBGE. Cidades@: Ceará Barbalha. Disponível em: <http://cidades.ibge.gov.br/xtras/perfil. php?lang=\&codmun=230190 > . Acesso em: 14 abr. 2015.

LEFEVRE, F.; LEFEVRE, A. M. C. O que é o DSC/ Qualiquantisoft. São Paulo: Instituto de Pesquisa do Discurso do Sujeito Coletivo, 2015.

MACEDO, D. G. Bioprospeç̧ão, disponibilidade e conservação de plantas medicinais em um encrave de cerrado na Chapada do Araripe, Nordeste do Brasil. 2013.149 f. Dissertação (Mestrado em Bioprospecção Molecular) Universidade Regional do Cariri, Crato, 2013.

MACEDO, M.; FERREIRA, A. R. Plantas hipoglicemiantes utilizadas por comunidades tradicionais na $\mathrm{Ba}$ cia do Alto Paraguai e Vale do Guaporé, Mato Grosso - Brasil. Revista Brasileira de Farmacognosia, Maringá, v. 14, p. 45-47, 2005. Suplemento 1. http://dx.doi. org/10.1590/S0102-695X2004000300017.

MACIEL, M. A. M. et al. Plantas medicinais: a necessidade de estudos multidisciplinares. Química Nova, São Paulo, v. 25, n. 3, p. 429-438, 2002.

NEGRI, J. R. et al. Perfil sociodemográfico e ocupacional de trabalhadores com ler/dort: estudo epidemiológico. Revista Baiana de Saúde Pública, Salvador, v. 38, n. 3, p. 555-570, 2014. http://dx.doi.org/10.5327/Z01000233-2014380300005.

OLIVEIRA, D. R. et al. A etnofarmacológico de plantas medicinais em infecçóes geniturinárias por moradoras da Chapada do Araripe, Crato, Ceará - Brasil. Revista Brasileira em Promoção da Saúde, Fortaleza, v. 25, n. 3, p. 278-286, 2012.

PEREIRA, B. E.; DIEGUES, A. C. Conhecimento de populaçóes tradicionais como possibilidade de conservação da natureza: uma reflexão sobre a perspectiva da etnoconservação. Desenvolvimento e Meio Ambiente, Campinas, n. 22, p. 37-50, 2010.

PHILLIPS, O.; GENTRY, A. H. The useful plants of Tambopata, Peru: I. Statistical hypotheses tests with a new quantitative technique. Economic Botany, Peru, v. 47, n. 1, p. 15-32, 1993.

POSEY, D. Introdução - Etnobiologia: teoria e prática. In: RIBEIRO, B. (Ed.). Suma etnológica brasileira: etnobiologia. Petrópolis: Vozes, 1987. p. 15-25.

RIBEIRO, S. C. Etnogeomorfologia sertaneja: proposta metodológica para a classificaçáo das paisagens da subbacia do rio Salgado- CE. 2012. 200 f. Tese (Doutorado 
em Geografia) - Universidade Federal do Rio de Janeiro, Rio de Janeiro, 2012.

SANTOS, J. F.; LIMA NETO, J. S. Análise de prevalência de ler/dort e sua influência na capacidade para o trabalho e na qualidade de vida de trabalhadores rurais. Cadernos de Educação, Saúde e Fisioterapia, Porto Alegre, v. 1, n. 1, p. 112-126, 2014.

SANTOS, R. E. F.; SENA, P. S. Base territorial da Mata Atlântica. Etno-ecologia da argila branca na tribo Tupiguarani (séculos XIV e XV). Janus, Lorena, v. 1, n. 11, p. 107-120, 2010.

SZABÓ, T. Ethnobiodiversity and plant genetic resources in the Alp-Balkan-Carpath-Danube (ABCD) area. Revue de Géographie Alpine, Anné, v. 86, n. 4, p. 131140, 1998.
VAZ, R. S. C. A atuação da terapia ocupacional no Centro de Referência em Saúde do Trabalhador: uma revisão bibliográfica (2007 a 2014). 2015. 38 f. Monografia (Bacharelado em Terapia Ocupacional) - Universidade de Brasília, Brasília, 2015.

WALCKER, L. P.; ROMÃO, A. Análise das sensaçóes físicas de agricultores da região de cascavel em relação às máquinas agrícolas utilizadas. In: ENCONTRO NACIONAL DE ENGENHARIA DE PRODUÇÃO MATURIDADE E DESAFIOS DA ENGENHARIA DE PRODUÇÃO, 30., 2010, São Carlos. Anais... São Carlos: ABEPRO, 2010. Disponível em: <http:// www.abepro.org.br/biblioteca/enegep2010_TN_ STO_116_757_16001.pdf>. Acesso em: 14 abr. 2015.

\section{Contribuição dos Autores}

Nyrreyne Dias Pereira de Melo: concepção do texto, organização de fontes. Arthur Bezerra Barros: análises do texto. Simone Cardoso Ribeiro: revisão do texto. Todos os autores aprovaram a versão final do texto.

\section{Notas}

${ }^{1}$ Imersão da planta ou substância aromática em água quente ou a ferver.

${ }^{2}$ Imersão do vegetal em solvente em ebulição, semelhante à infusão; coloca-se o vegetal junto com a água para ferver.

${ }^{3}$ Imersão do vegetal em água fria.

${ }^{4}$ Remédio Caseiro conhecido também por xarope. 